\title{
The Need for Specific Modeling of Small Enterprise Default Prediction: Empirical Evidence from Italian Small Manufacturing Firms
}

\author{
Francesco Ciampi ${ }^{1}$ \\ ${ }^{1}$ Department of Economics and Business, Florence University, Florence, Italy \\ Correspondence: Francesco Ciampi, Department of Economics and Business, Florence University, Florence, \\ Italy. E-mail: francesco.ciampi@unifi.it
}

Received: November 14, 2017

Accepted: November 24, 2017

Online Published: November 28, 2017

doi:10.5539/ijbm.v12n12p251

URL: https://doi.org/10.5539/ijbm.v12n12p251

\begin{abstract}
The existing literature has proved the effectiveness of financial ratios for company default prediction modelling. However, such researches rarely focus on small enterprises (SEs) as specific units of analysis. The aim of this paper is to demonstrate that SE default prediction should be modelled separately from that of large and medium-sized firms. In fact, a multivariate discriminant analysis was applied to a sample of 2,200 small manufacturing firms located in Central Italy and a SE default prediction model was developed based on a selected group of financial ratios and specifically constructed to capture the specificities of SEs' risk profiles. Subsequently, the prediction accuracy rates obtained by this model were compared with those obtained from a second model based on a sample of 3,200 manufacturing firms situated in Central Italy which belong to all dimensional classes. The findings are the following: 1) evaluating the probability of default of SEs separately from that of larger firms improves prediction performance; 2) the predictive power of the discriminant function improves if it takes into account the different profiles of firms operating in different industry sectors; 3) this improvement is much greater for SEs compared to larger firms.
\end{abstract}

Keywords: bankruptcy, credit rating, default prediction modelling, financial ratios, small enterprise

\section{Introduction}

The effectiveness of financial ratios for company default prediction modelling has long been analyzed and assessed in literature (e.g., Altman, 1968; Aaron, Nainggolan, \& Trinugroho, 2017; Beaver, 1966; Blum, 1974; Figini, Savona, \& Vezzoli, 2016; Grice, \& Ingram, 2001; Gupta, 2014; Huijuan, 2015; Ohlson, 1980; Pindado \& Rodrigues, 2008; Traczynski, 2017).

SEs constitute a relevant part of every national economic system (Berger \& Scott 2007). Considering the definition of small enterprises (SEs) used in this study (companies with a turnover of less than 10 million euros), in Italy about $95 \%$ of all firms are SEs and they employ about $79 \%$ of the workforce.

SEs have markedly different characteristics if compared to medium and large enterprises. For example, SEs are normally quicker and more flexible when reacting to environmental (competitive, technological, social, etc.) changes and have a notably "personal" character, with owners and managers who are often one and the same people (Burke \& Jarrat 2004; Ciampi, 2015). From this it follows that building and testing instruments specifically developed in order to capture, interpret and asses these particular characteristics represent promising research exercises (Ciampi \& Gordini, 2013).

Nevertheless, the literature regarding corporate bankruptcy prediction modelling is almost totally based on samples of large firms. Aiming to give a contribution to fill this gap, this study applies a discriminant analysis to a sample of 2,200 small manufacturing firms located in Central Italy and builds a SE default prediction model based on an appropriately selected group of financial ratios, specifically constructed to capture the specificities of SE risk profiles. It then compares the accuracy rates obtained by this model with those from a second model based on a sample of 3,200 manufacturing firms situated in Central Italy belonging to all dimensional classes. The large size of the two samples gives considerable weight to the reliability of the findings of this research project. 
The purpose of this paper is to demonstrate that modelling the probability of default of small firms separately from that of larger firms improves the predictive performance of the models. Moreover, the predictive power of the discriminant function improves if it takes into account the different profiles assumed by firms operating in different industry sectors and this improvement is much more significant for SEs compared to larger firms.

The literature review on bankruptcy prediction modelling in the next part of this paper will focus on the scarce research on SME default prediction modelling. In section 3, two research hypotheses will be proposed. Subsequently, the sample analysed will be described and the selected predictive variables presented. Finally, the research findings will be discussed and conclusions presented.

\section{Literature Review}

There is extensive literature about company failure prediction modelling. However, most of the studies aim to develop prediction models for large and/or listed firms and/or are mainly based on samples of large firms (e.g. Altman, 1968; Beaver, 1966; Blum, 1974; Grice \& Ingram, 2001; Ohlson, 1980; Pindado \& Rodrigues, 2008).

Beaver (1966), using a univariate discriminant analysis, examined a sample of 79 large firms which failed in the period from 1954 to 1964 and compared them with a sample of 79 companies which did not fail in that same period. He tested the predictive effectiveness of 14 financial ratios and found that the cash flow to total debt ratio correctly classified 87 (78) percent of the firms one year (five year) before bankruptcy.

Altman (1968), using a multiple discriminant analysis, studied a sample of 33 large manufacturing firms which failed during the period 1946-1965, and a stratified sample of 33 manufacturing firms which did not fail. He analyzed an initial set of 22 financial ratios and built a model based on five discriminant ratios, whose prediction accuracy tested on a holdout sample of 66 firms was $79 \%$ one year before failure.

Blum (1974) analyzed a sample of 115 large manufacturing companies which failed in the period 1954-1968 and a stratified sample of 115 non-failed firms which were similar in terms of turnover, number of employees and industry. The predictive accuracy of Blum's discriminant function was $93-95 \%$ one year before failure, $80 \%$ two years before failure, and $70 \%$ three years before failure.

Apart from the contribution by Edmister (1972), only a few and relatively recent studies have focused on small and medium sized enterprises default prediction modelling (Altman \& Sabato, 2007; Ciampi, 2015; Ciampi \& Gordini, 2013). Edmister (1972) analysing a sample of 562 SMEs during the period 1956-1969 and using the multivariate discriminant analysis, built a SME default prediction model based on 18 financial ratios. Altman and Sabato (2007), analysing a sample of 2,010 US SMEs during the period 1994-2002 and using logistic regression, developed a one-year SME default prediction model based on financial ratios and found that it increased SME failure prediction accuracy.

Nevertheless, in spite of the importance of SEs for the economy and the industrial system of all the developed countries, failure prediction modelling specifically designed to capture particular credit risk profiles of this category of firms still represents a largely unexplored research filed.

\section{Hypotheses}

Small firms have markedly different characteristics if compared to medium and large enterprises. SEs are normally quicker and more flexible when reacting to environmental (competitive, technological, social, etc.) changes and have a notably "personal" character, with owners and managers who are often one and the same people (Ciampi 2015; Burke\& Jarrat 2004). The SE growth is a result of clear, positively motivated business intentions and actions on the part of the owner-manager, driven by the belief that he can produce the desired outcomes (Morrison, Breen, \& Ali 2003). Small entrepreneurs, at the same time, especially when facing growing processes, often experience difficulties in managing all the information they need in order to consciously take all the required decisions. Furthermore, although they often have excellent production competences, they are not sufficiently endowed with adequate management skills regarding organization, marketing and, most of all, finance. As a result, SEs are very often undercapitalized, find it difficult to access long-term credit financing, with the consequence that short term bank financing normally represents the principal financial source available which often ends up being incorrectly used to cover medium and long term financial needs (Ciampi, 1994). Finally, SEs, besides being more financially opaque than larger companies (Berger \& Frame 2007), are physiologically subjected to bear greater impacts of external events compared to larger companies: the consequence is that when a small firm is predicted to fail (or not to fail), there is a greater probability that the prediction will be wrong because external events might suddenly save the firm from failure or, alternatively, lead the company to unexpected bankruptcy.

Based on these considerations, it is reasonable to expect a higher SE default prediction accuracy for models built 
on the basis of a sample composed only of SEs compared to a model based on a sample composed of firms belonging to all dimensional classes. Consequently, the following hypothesis is formulated:

H1: When default prediction models are based on a sample consisting exclusively of small firms, SE default prediction accuracy rates will be significantly higher compared to models based on a sample composed of firms belonging to all dimensional classes.

Furthermore, SEs are more subject to adapting their structures, strategies and financial profiles to the different contexts characterizing the diverse industrial environments (Ciampi, 2015). On this basis, and considering that the structure of the sample regarding business sectors influences the accuracy of a prediction model, the second research hypothesis is:

H2: When discriminant functions are separately calculated for different manufacturing sectors, accuracy rates are higher than when functions are based on the aggregate sample (H2A), and the obtainable increases in prediction accuracy are higher when prediction models are built on the basis of a sample consisting exclusively of small firms than when they are based on a sample composed of firms belonging to all dimensional classes (H2B).

\section{Method}

\subsection{The Sample Analyzed}

The population analyzed in this study includes all firms in the CERVED Database (Note 1) which are situated in Central Italy, operate in one of the manufacturing sectors included in Table 1 and had a turnover in 2012 of less than 10 million euros.

Table 1. Manufacturing categories.

\begin{tabular}{cl}
\hline Categories & Sectors \\
\hline 1 & Food \\
2 & Clothing \\
3 & Wood products \\
4 & Chemical products \\
5 & Metallurgy \\
6 & Mechanical machines \\
7 & Electric, electronic and optical machines and tools \\
\hline
\end{tabular}

The sample used for building prediction models (training sample) consisted of 2,200 small manufacturing companies, of which 1,100 defaulted during the year 2016 and 1,100 did not (Note 2) during the same year. The training sample was selected using the case-control approach. Two groups of subjects were selected: a group of firms which failed in 2016 (the cases) and a group of firms with very similar characteristics (levels of turnover, business sector and geographical location) which did not fail in the same year (the controls).

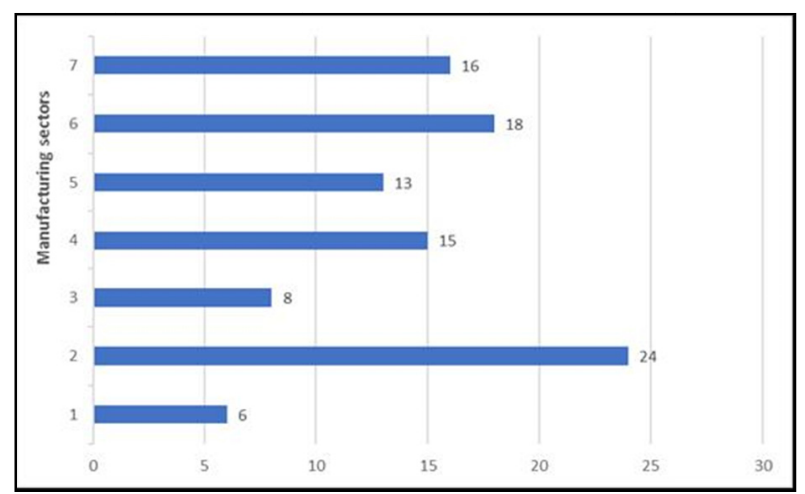

Figure 1. Percentage distribution of insolvent firms by manufacturing category

Bankruptcies occur rather infrequently and in literature default prediction models are often estimated from 
samples with a proportion of bankrupt firms much larger than the fraction of such firms in the population (Skogsvik \& Skogsvik, 2013). Nevertheless, in a relevant part of this literature (e.g., Altman, 1968; Beaver, 1966; Edmister, 1972; Fulmer, Moon, Gavin, \& Erwin, 1984; Pindado \& Rodrigues, 2004; Pompe \& Bilderbeek, 2005; Zenzerović, 2009) a "matched-pairs" design was used, implying a sample with $50 \%$ of the observations coming from bankrupt firms. The main aim of this research is to highlight the effect of a group of independent variables (financial ratios) on the likelihood that a small firm may fail, and not to represent (and investigate) the behaviour of the entire population of Italian small firms. Thus, in line with the above mentioned literature, the sample of 2,200 small firms had $50 \%$ of the observations in the bankrupt group and $50 \%$ of the observations in the non-bankrupt group (even if the proportion of non-bankrupt firms in the entire population is obviously much higher than $50 \%$ ).

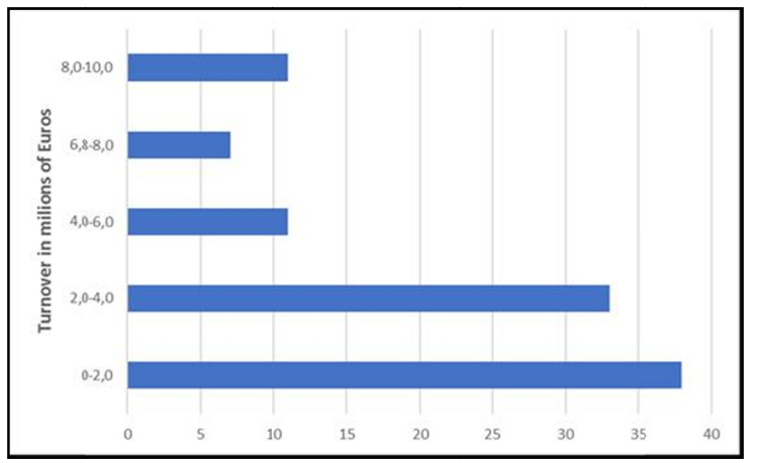

Figure 2. Percentage distribution of insolvent firms by 2012 turnover

The defaulted firms were selected from the CERVED Database using a proportional random sampling method aimed at maximizing the representativeness with regard to the following three stratification criteria: business sector (Figure 1), size in terms of 2012 turnover (Figure 2) and geographical location (region of Central Italy (Note 3 ) in which the firm is located).

As shown in Figure 1, the highest percentages of failing firms operated in the clothing sector ( $24 \%$ of all "cases") and mechanical machines (18\%); the 2012 turnover of these firms was quite small: about $71 \%$ of them had a turnover lower than 4 million euros (Figure 2).

The control group (not defaulted firms in 2016) was also selected from the CERVED Database using a proportional stratified random sampling method, with the aim of replicating the composition of the failed firms in terms of levels of the 2012 turnover, geographical location and business sector.

The effectiveness of the prediction models developed in this study was tested on a holdout sample consisting of 1,500 small manufacturing companies, of which 750 defaulted during the year 2016 and 750 did not default during the same year. This sample was selected from the CERVED Database by using the same criteria adopted to build the training sample (random sampling stratified in terms of business sector, turnover and geographical location).

In order to verify if discriminant functions specifically based on a sample consisting exclusively of SEs really have significantly higher accuracy rates compared to functions based on a sample composed of firms belonging to all dimensional classes, a second population was contemporarily analyzed, including all small, medium and large enterprises (SMLEs) from the CERVED Database which, regardless of their 2016 turnover, were situated in Central Italy and operated in one of the manufacturing sectors included in Table 1. With regard to this second population:

1) A training sample consisting of 3,200 SMLEs was extracted, of which 1,600 defaulting enterprises during the year 2016 and 1,600 non-defaulting ones during the same year. Here too the training sample was selected using the case-control approach: the failed firms were chosen using a proportional random sampling method aimed at maximizing the representativeness with regard to the same three stratification criteria (business sector, 2012 turnover categories and geographical location); the control group (not failed firms in 2016) was selected with the aim of replicating the composition of the failed firms using the same three criteria;

2) Subsequently, the same criteria were adopted to select the training sample a holdout sample consisting of 
1,600 small, medium and large manufacturing companies, of which 800 defaulting enterprises during the year 2016 and 800 non-defaulting ones during the same year.

\subsection{Default Predictors}

The potentially predictive variables examined were a group of financial ratios calculated on balance sheet data relating to the 2012 financial year, i.e. four years before the failed firms went into bankruptcy. An initial group of 19 financial ratios was selected (Table 2) as possible predictors (independent variables) considering the frequency with which they had previously proved to be effective in the context of the existing literature (Altman, 1968; Altman, 1993; Altman, Brady, Resti, \& Sironi, 2005; Altman, Haldeman, \& Narayanan, 1977; Altman \& Sabato, 2005, 2006; Beaver, 1966; Blum, 1974; Crouhy, Mark, \& Galai, 2001; Edmister, 1972), as well as the opportunity to cover the three fundamental areas of company balances: liquidity, leverage and profitability.

Table 2. Initial group of potential predictors examined

\begin{tabular}{ll}
\hline X1 & ROE $=$ Net Profit/E \\
\hline X2 & ROI $=$ Ebit/Net Operative Assets \\
X3 & ROS = Ebit/Turnover \\
X4 & VA/Turnover \\
X5 & Ebitda/Turnover \\
X6 & IE/Turnover \\
X7 & IE/Ebitda \\
X8 & Turnover/Number of Employees \\
X9 & VA/Number of Employees \\
X10 & Cash Flow/ TD \\
X11 & ROD = IE/TD \\
X12 & IE/BL \\
X13 & BL/Turnover \\
X14 & NFP/Turnover \\
X15 & TD/E \\
X16 & Financial Debts/E \\
X17 & TD/Ebitda \\
X18 & E/Long-Term Assets \\
X19 & ATR = (Current Assets - Inventories)/Current Liabilities \\
\hline
\end{tabular}

Note. $\mathrm{VA}=$ value added; $\mathrm{IE}=$ interest expense;

$\mathrm{FC}=$ fixed costs $; \mathrm{TD}=$ total debts $; \mathrm{E}=$ equity;

$\mathrm{NFP}=$ net financial position; $\mathrm{BL}=$ bank loans;

$\mathrm{EBIT}=$ operat. revenue - operat. expenses + not operat. income;

EBITDA $=$ ebit + depreciation + amortization; ATR $=$ acid test ratio

The initial number of these potential failure predictors was progressively reduced based on the results of the variance inflation factor (VIF) method and the stepwise method (SM), separately applied to the above described training SE sample (consisting of 2,200 firms) and SMLE sample (consisting of 3,200 firms).

\begin{tabular}{|c|}
\hline Initial group of financial ratios based on: \\
\hline -frequency in the literature \\
\hline -ability to cover the three fundamental areas of company balances \\
\hline$\downarrow$ \\
\hline Univariate Analysis \\
\hline$\downarrow$ \\
\hline Variance Inflation Factor $(\mathrm{VIF}<=6)$ \\
\hline$\downarrow$ \\
\hline Stepwise Method \\
\hline
\end{tabular}

Figure 3. Selection of failure predictors 


\subsubsection{Univariate Analysis}

Table 3 reassumes the distribution of the 2012 mean and median values assumed in the two SE training sub-samples by each analyzed indicator. As expected, the defaulting SEs: (1) had a much higher level of financial leverage in terms of both Total Debts/Equity ratio (X15) and Financial Debt/Equity ratio (X16); (2) a much lower level of profitability in terms of both ROE (X1) and ROI (X2); (3) a much worse situation regarding liquidity (average Acid Test ratio is 0.474 for defaulting firm and 0.976 for non-defaulting firms)

Table 3. Financial ratios in SEs: 2012 mean and median values

\begin{tabular}{lllll}
\hline & \multicolumn{2}{l}{ Defaulting firms } & \multicolumn{2}{l}{ Non-defaulting firms } \\
& Mean & Median & Mean & Median \\
\hline X1 & -0.126 & -0.115 & 0.098 & 0.070 \\
X2 & 0.231 & 0.166 & 0.391 & 0.256 \\
X3 & 0.050 & 0.050 & 0.077 & 0.065 \\
X4 & 0.119 & 0.113 & 0.224 & 0.211 \\
X5 & 0.070 & 0.065 & 0.100 & 0.098 \\
X6 & 0.048 & 0.018 & 0.019 \\
X7 & 0.052 & 0.385 & 0.178 & 0.159 \\
X8 & 0.491 & 1.805 & 4.756 & 4.544 \\
X9 & 2.733 & 0.485 & 0.878 & 0.759 \\
X10 & 0.591 & 0.032 & 0.083 & 0.078 \\
X11 & 0.046 & 0.237 & 0.212 \\
X12 & 0.034 & 0.138 & 0.072 & 0.070 \\
X13 & 0.055 & 0.236 & 0.969 & 0.990 \\
X14 & 0.122 & -0.179 & -0.069 & -0.059 \\
X15 & 0.232 & 7.340 & 3.635 & 3.123 \\
X16 & -0.171 & 2.132 & 0.558 & 0.472 \\
X17 & 8.539 & 6.655 & 4.269 & 3.370 \\
X18 & 2.173 & 0.821 & 2.592 & 2.092 \\
X19 & 5.927 & 0.465 & 0.976 & 0.954 \\
\hline
\end{tabular}

\subsubsection{VIF Method and Stepwise Analysis}

The use of the VIF Method (Table 4) made it possible to remove the following financial ratios with Variance Inflation Factor higher than 3 (Pompe \& Bilderbeek, 2005): Cash Flow/Total Debt, Ebitda/Turnover, Banks Loan/Turnover, Turnover/Number of Employees and Value Added/Number of Employees).

The Principal Components Analysis proved to be of little use for this experiment as the "First Principal Component" and the "First Two Principal Components" explained only $19 \%$ and $29 \%$ of the total variance, respectively.

Table 4. Financial ratios in Small Enterprises: Multicollinearity test

\begin{tabular}{ll}
\hline & VIF \\
\hline CASH FLOW/TOTAL DEBTS & 11.114 \\
EBITDA/TURNOVER & 12.318 \\
VALUE ADDED/TURNOVER & 2.245 \\
INTEREST EXPENSE/TURNOVER & 1.640 \\
INTEREST EXPENSE /EBITDA & 1.338 \\
ROS & 2.667 \\
ROI & 2.450 \\
ROE & 1.631 \\
ROD & 1.437 \\
INTEREST EXPENSE/BANK LOANS & 1.457 \\
BANK LOANS/TURNOVER & 6.180 \\
NET FINANCIAL POSITION/TURNOVER & 2.560 \\
\hline
\end{tabular}




\begin{tabular}{ll}
\hline TOTAL DEBTS/EQUITY & 2.190 \\
TOTAL DEBTS /EBITDA & 1.489 \\
FINANCIAL DEBTS /EQUITY & 2.827 \\
EQUITY/LONG TERM ASSETS & 1.978 \\
ACID TEST RATIO & 2.995 \\
TURNOVER/NUMBER OF EMPLOYEES & 6.226 \\
VALUE ADDED/NUMBER OF EMPLOYEES & 6.306 \\
\hline
\end{tabular}

By applying the Stepwise Method (Note 4) and by adding at each step of the process the financial ratio with the best performance of the $\mathrm{F}$ value (above the standard of 3.84), it was possible to reduce the discriminant variables to four (see Tables 5).

Table 5. Selection of SE default predictors with stepwise method

\begin{tabular}{lll}
\hline Steps & Entered Variables & P-Value \\
\hline 1 & ROI & 0.001 \\
2 & TD/E & 0.001 \\
3 & ROE & 0.000 \\
4 & BL/TURNOVER & 0.000 \\
\hline
\end{tabular}

Note. $\mathrm{TD}=$ total debts; $\mathrm{E}=$ equity $; \mathrm{BL}=$ bank loans.

Starting from the same initial group of 19 financial ratios contained in Table 2, the same selection process described in Figure 3 was applied to the SMLE training sample (consisting of 3,200 small, medium and large firms). The obtained results are synthetized in Table 6.

Table 6. Selection of SMLE default predictors with stepwise method

\begin{tabular}{lll}
\cline { 2 - 3 } Steps & Entered Variables & P-Value \\
\hline 1 & ROE & 0.001 \\
2 & NFP/Turnover & 0.001 \\
3 & ROI & 0.001 \\
4 & TD/Ebitda & 0.000 \\
\hline
\end{tabular}

Note. $\mathrm{NFP}=$ net financial position; $\mathrm{TD}=$ total debts;

$\mathrm{EBITDA}=$ ebit + depreciation + amortization

\subsection{Statistical Method}

Many different techniques and predictive variables have been proposed in literature for company default prediction modelling. The multivariate discriminant analysis (MDA) has been the most frequently used technique (Altman, 1968; Altman et al., 1977; Blum, 1974; Deakin, 1972; Edmister, 1972; Rosenberg, \& Gleit, 1994); some studies used logistic regression analysis (Ohlson, 1980), Artificial Neural Networks (Zhang, Hu, Patuwo, \& Indro, 1999; Ciampi \& Gordini, 2013), and a back-propagation neural network (Tam, 1991). Following the more traditional literature, a multivariate discriminant analysis has been used in this study.

\section{Research Findings}

\subsection{Results}

Table 7 shows the results of the validity tests (Note 5) implemented in order to verify the predictive power (tested on the holdout sample) for small enterprises (firms with a turnover of less than 10 million euros) of both the SE discriminant function (i.e. the function based on the training sample consisting exclusively of SEs) and the SMLE discriminant function (i.e. the function based on the training sample composed of firms belonging to all dimensional classes). 
Table 7. Validity test for small firms of the SE and SMLE discriminant functions

\begin{tabular}{llllll}
\hline & SE & observed & \multicolumn{2}{l}{ SE predicted state } & $\begin{array}{l}\text { Percentage of correctly } \\
\text { classified SEs }\end{array}$ \\
& state & 0 & 1 & $78.50 \%$ \\
SMLE discriminant functions & 0 & $79.20 \%$ & $20.80 \%$ & \\
\multirow{2}{*}{ SE discriminant functions } & 1 & $22.20 \%$ & $77.80 \%$ & \\
& 0 & $81.26 \%$ & $18.74 \%$ & $80.58 \%$ \\
\hline
\end{tabular}

The SE Observed State 0 lines show the percentage of correctly classified failed companies and the percentage of misclassified failed firms (Type 1 error). The SE Observed State 1 lines show the percentage of misclassified non-failed firms (Type 2 error) and the percentage of correctly classified non-filed firms. The last column of the table shows the function's overall prediction accuracy (percentage of correctly classified SEs).

The validity test on the SE discriminant function gives a global accuracy level of $80.58 \%$ with $18.74 \%$ of Type 1 errors and 20,10\% Type 2 errors, while the same test on the SMLE discriminant function gives 20,80\% Type 1 errors, $22,20 \% \%$ Type 2 errors and an overall accuracy of $78.5 \%$. These results confirm H1: small firms have their own specific structural and strategic characteristics, which are unlike those of large firms (Ciampi, 1994; Ciampi, 2015; Pompe \& Bilderbeek, 2005) and consequently their credit risk profiles are significantly different from larger companies. Financial institutions should therefore use credit rating models specifically built for SEs in order to maximize their capacity to create value for their shareholders (Altman \& Sabato, 2007).

Table 8 shows that Class 4 size group has the highest prediction accuracy rates $(80,80 \%$ for the SMLE discriminant function and $82.90 \%$ for the SE discriminant function). Class 2 size group shows the lowest prediction accuracy rates $(74.20 \%$ and $76.20 \%$ respectively).

Table 8. Validity test for small firms of the SE and SMLE discriminant functions for each size group (percentages)

\begin{tabular}{llll}
\hline & \multicolumn{2}{l}{ Percentage of correctly classified } \\
Size Groups & $\begin{array}{l}\text { SEs by SMLE discriminant } \\
\text { function }\end{array}$ & $\begin{array}{l}\text { Percentage of } \\
\text { classified SEs by } \\
\text { discriminant function }\end{array}$ \\
\hline Class 1 $(0,0-2,0)^{*}$ & $77.40 \%$ & $79.78 \%$ \\
Class 2 $(2,0-4,0)^{*}$ & $74.20 \%$ & $76.20 \%$ \\
Class 3 $(4,0-6,0)^{*}$ & $79.90 \%$ & $82.10 \%$ \\
Class 4 $(6,0-8,0)^{*}$ & $80.80 \%$ & $82.90 \%$ \\
Class 5 $(8,0-10,0)^{*}$ & $80.20 \%$ & $81.90 \%$ & \\
Mean & $78.50 \%$ & $80.58 \%$ & \\
\hline
\end{tabular}

* Turnover in millions of Euros.

Table 9. Validity test for small firms of the SE and SMLE discriminant functions calculated separately for each manufacturing category

\begin{tabular}{lll}
\hline $\begin{array}{l}\text { Manufacturing } \\
\text { categories }\end{array}$ & $\begin{array}{l}\text { Percentage of correctly classified SEs by } \\
\text { SMLE discriminant functions }\end{array}$ & $\begin{array}{l}\text { Percentage of correctly classified SEs by SE } \\
\text { discriminant functions }\end{array}$ \\
\hline 1 & $84.20 \%$ & $88.70 \%$ \\
2 & $88.30 \%$ & $89.20 \%$ \\
3 & $89.50 \%$ & $93.50 \%$ \\
4 & $88.50 \%$ & $96.30 \%$ \\
5 & $88.70 \%$ & $96.20 \%$ \\
6 & $87.30 \%$ & $91.50 \%$ \\
7 & $81.30 \%$ & $90.70 \%$ \\
Mean & $86.83 \%$ & $92.30 \%$ \\
\hline
\end{tabular}

Table 9 shows that by applying a discriminant analysis separately for the different manufacturing sectors indicated in Table 1: 
a) Both the SE models and the SMLE models prove that prediction accuracy rates (checked on the hold out sample) are higher when the discriminant functions are calculated on the aggregate training samples, confirming $\mathrm{H} 2 \mathrm{~A}$. Consequently, it is essential that credit rating takes the business sector in which a firm operate into account;

b) More importantly, the increases in prediction accuracy are higher for the SE discriminant functions (the SE model gives a mean increase of 14,55\%) compared to the SMLE discriminant functions (the SMLE model gives a mean increase of 10,61\%), thus confirming H2B. Small firms are more subject than larger firms to adapt their structures, strategic behaviors and financial profiles to the different industrial contexts in which they operate (Ciampi, 2015); as a consequence, pooling (separating) different business sectors reduces (improves) a model's prediction accuracy especially in the case of SEs.

\subsection{Robustness Checks}

Finally, in order to test how the proposed models would react to different stimuli, the robustness of these findings was tested on different holdout samples and in a different period of time (2008-2012). SE hold-out sample 2 consisted of 1400 small manufacturing firms operating in Central Italy. 700 of these firms were in bonis at the end of 2012 and 700 had become insolvent in 2012. SMLE hold-out sample 2 consisted of 1300 small, medium and large manufacturing firms operating in Central Italy. 650 of these firms were in bonis at the end of 2012 and 650 had become insolvent in 2012. Ratios were calculated on balance sheet data for the 2008 trading year. The results obtained confirm both hypotheses: the SE discriminant function gives a global accuracy level $(79.92 \%)$ higher than the accuracy level of the SMLE discriminant function (78,32\%); prediction accuracy rates improve when a discriminant analysis is applied to separate manufacturing categories; moreover, this improvement is much higher for the SE model $(+14,13 \%)$ compared to the SMLE model $(+10,32 \%)$.

\section{Conclusions}

Building effective models for corporate default prediction is a strategic issue for banks when evaluating their present and potential clients, as well as for rating agencies. This issue has become increasingly important in recent years, as the Basel Capital Accords directly linked the capital requirements of financial institutions to the level of risk of their customers, and allowed banks to use internally built credit risk evaluation models to quantify their capital requirements, thereby encouraging a more accurate monitoring of the quality of their loans (Altman \& Sabato, 2007).

The specific characteristics of SMEs and the fact that they play an important role in the world's economy are factors which make it essential for both banks and academics to construct and test default prediction models that are specific for SMEs (Ciampi, 2015).

The principal aim study was to develop a prediction model specifically based on SEs and verify if it performed better than a model built on the basis of a sample composed of firms belonging to all dimensional classes. Two prediction functions were constructed, one specifically based on a training sample consisting exclusively of SEs (which consequently incorporated the specific characteristics of small firms) and the other based on a training sample composed of firms belonging to all dimensional categories.

The findings of this research contribute to the literature on the small company default prediction modelling as follows. First, they confirm that small firms have significantly different credit risk profiles compared to larger companies. When evaluating the probability of a small firm's default, financial institutions should take into account these differences if they want to maximize their capacity to create value for their shareholders.

Second, they demonstrate that for firms belonging to all dimensional categories, prediction accuracy improves when the discriminant analysis is applied to separate manufacturing categories: this means that pooling different business sectors tends to reduce a model's prediction accuracy.

Third, the fact that the above mentioned improvement is much greater for the SE model compared to the SMLE model confirms that the business sector effect is particularly important in the case of SEs.

Fourth, the findings confirm that financial ratios can be effective tools in SE default prediction modelling. In fact, the overall prediction accuracy rates of the analyzed two models are highly satisfactory.

However, this study has some limitations. First, it analyses firms in only one geographical context (Central Italy). The specific characteristics regarding the economic and industrial structure, in this context (i.e. a poor capital market orientation, with a significant role in corporate finance played by banks; a scarcely efficient market for corporate control; the fact that control is very often maintained through a high concentration of ownership) clearly influence which financial mechanism and ratios have an effect on the probability of a firm's default and 
in what way these mechanisms and ratios have an effect. These aspects limit the generalization of the validity of the findings of this study.

Second, prediction models are built using the discriminant analysis and some questions have been raised as to whether this method is effectively applicable when the prediction variables adopted refer to balance sheet ratios which are not linear, and normal, and are not completely independent of one another (Ohlson, 1980).

Third, the constant and significant presence of classification errors (both Type I and Type II errors) points to the need to increase the categories of the predictive variables used for SE default prediction modelling, so as to also include qualitative characteristics relating to company organizational structure and competitive strategy (Ciampi, 2015).

\section{References}

Aaron, A., Nainggolan, Y. A., \& Trinugroho, I. (2017). Corporate Failure Prediction Model in Indonesia: Revisiting the Z-Scores, Discriminant Analysis, Logistic Regression and Artificial Neural Network. Journal for Global Business Advancement, 10(2), 187-209. http://dx.doi.org/10.1504/JGBA.2017.10004077

Altman, E. I. (1968). Financial Ratios, Discriminant Analysis and the Prediction of Corporate Bankruptcy. The Journal of Finance, 23(4), 589-609. http://dx.doi.org/10.1111/j.1540-6261.1968.tb00843.x

Altman, E. I. (1993). Corporate Financial Distress and Bankruptcy (2nd ed.). New York, NY: Wiley.

Altman, E.I., Brady, B., Resti, A., \& Sironi, A. (2005). The Link between Default and Recovery Rates: Theory, Empirical Evidence, and Implications. The Journal of Business, 78(6), 2203-2228. http://dx.doi.org/10.1086/497044

Altman, E. I., Haldeman, R. G., \& Narayanan, P. (1977). Zeta-analysis. A New Model to Identify Bankruptcy Risk of Corporations. Journal of Banking and Finance, 1(1), 29-54. http://dx.doi.org/10.1016/0378-4266(77)90017-6

Altman, E. I., \& Sabato, G. (2005). Effects of the New Basel Capital Accord on Bank Capital Requirements for SMEs. Journal of Financial Services Research, 28(1-3), 15-42. http://dx.doi.org/10.1007/s10693-005-4355-5

Altman, E. I., \& Sabato, G. (2007). Modeling Credit Risk for SMEs: Evidence from the US Market. Abacus, 43(2), 332-357. http://dx.doi.org/10.1111/j.1467-6281.2007.00234.x

Beaver, W. (1966). Financial Ratios Predictors of Failure. Journal of Accounting Research, 4, 71-111. https://doi.org/10.2307/2490171

Berger, A. N., \& Frame, S. W. (2007). Small Business Credit Scoring and Credit Availability. Journal of Small Business Management, 45(1), 5-22. http://dx.doi.org/10.1111/j.1540-627X.2007.00195.x

Blum, M. (1974). Failing Company Discriminant Analysis. Journal of Accounting Research, 12(1), 1-25. http://dx.doi.org/http://dx.doi.org/10.2307/2490525

Burke, I. G., \& Jarrat, D. (2004). The Influence of Information and Advice on Competitive Strategy Definition in Small and Medium Sized Enterprises. Qualitative Market Research, 7(2), 126-138. http://dx.doi.org/10.1108/13522750410530039

Ciampi, F. (1994). Squilibri di assetto finanziario nelle P.M.I. Finanziamenti e contributi della Comunità Europea [Small Enterprise Financial Imbalances. European Community Funding]. Studi e Informazioni, 3, 1-129.

Ciampi, F. (2015). Corporate Governance Characteristics and Default Prediction Modeling for Small Enterprises. An Empirical Analysis of Italian Firms. Journal of Business Research, 68(5), 1012-1025. http://dx.doi.org/10.1016/j.jbusres.2014.10.003

Ciampi, F., \& Gordini, N. (2013). Small Enterprise Default Prediction Modeling through Artificial Neural Networks: An Empirical Analysis of Italian Small Enterprises. Journal of Small Business Management, 51(1), 23-45. http://dx.doi.org/10.1111/j.1540-627X.2012.00376.x

Crouhy, M., Galai, D., \& Mark, R. (2001). Prototype Risk Rating System. Journal of Banking and Finance, 25(1), 47-95. http://dx.doi.org/10.1016/S0378-4266(00)00117-5

Deakin, E. B. (1972). A Discriminant Analysis of Predictors of Business Failure. Journal of Accounting Research, 10(1), 167-179. http://dx.doi.org/10.2307/2490225

Edmister, R. O. (1972). An Empirical Test of Financial Ratio Analysis for Small Business Failure Prediction. Journal of Financial and Quantitative Analysis, 7(2), 1477-1493. http://dx.doi.org/10.2307/2329929. 
Figini, S., Savona, R., \& Vezzoli, M. (2016). Corporate Default Prediction Model Averaging: A Normative Linear Pooling Approach. Intelligent Systems in Accounting, Finance and Management, 23(1-2), 6-20. http://dx.doi.org/10.1002/isaf.1387

Fulmer, J. G. Jr., Moon, J. E., Gavin, T. A., \& Erwin, M. J. (1984). A Bankruptcy Classification Model for Small Firms. The Journal of Commercial Bank Lending, 66(11), 25-37.

Grice, J. S., \& Ingram, R. W. (2001). Tests of the Generalizability of Altman's Bankruptcy Prediction Model. Journal of Business Research, 54(1), 53-61. http://dx.doi.org/10.1016/S0148-2963(00)00126-0

Gupta, V. (2014), Analysis of Default Risk for Listed Companies in India: A Comparison of Two Prediction Models. International Journal of Business and Management, 9(9), 223-234. http://dx.doi.org/10.5539/ijbm.v9n9p223

Huijuan, L. (2015). Default Prediction Model for SME's: Evidence from UK Market Using Financial Ratios. International Journal of Business and Management, 10(2), 81-106. http://dx.doi.org/10.5539/ijbm.v10n2p81

Morrison, A., Breen J., \& Ali S. (2003). Small Business Growth: Intention, Ability, and Opportunity. Journal of Small Business Management, 41(4), 417-425. http://dx.doi.org/10.1111/1540-627X.00092

Ohlson, J. (1980). Financial Ratios and the Probabilistic Prediction of Bankruptcy. Journal of Accounting Research, 18(1), 109-131. http://dx.doi.org/10.2307/2490395

Pindado, J., \& Rodrigues, L. (2004). Parsimonious Models of Financial insolvency in Small Companies. Small Business Economics, 22(1), 51-66. http://dx.doi.org/10.1023/B:SBEJ.0000011572.14143.be

Pindado, J., Rodrigues, L., \& De la Torre, C. (2008). Estimating Financial Distress Likelihood, Journal of Business Research, 61(9), 995-1003. http://dx.doi.org/10.1016/j.jbusres.2007.10.006

Pompe, P. M., \& Bilderbeek, J. (2005). The Prediction of Bankruptcy of Small-and Medium-Sized Industrial Firms. Journal of Business Venturing, 20(6), 847-868. http://dx.doi.org/10.1016/j.jbusvent.2004.07.003

Rosenberg, E., \& Gleit, A. (1994). Quantitative Methods in Credit Management: A Survey. Operations Research, 42(4), 589-613. http://dx.doi.org/10.1287/opre.42.4.589

Skogsvik, K, \& Skogsvik, S. (2013). On the Choice Based Sample Bias in Probabilistic Bankruptcy Prediction. Investment Management and Financial Innovation, 10(1), 29-37.

Tam, K. Y. (1991). Neural Network Models and the Prediction of Bank Bankruptcy. OMEGA: The International Journal of Management Science, 19(5), 429-445. http://dx.doi.org/10.1016/0305-0483(91)90060-7

Traczynski, J. (2017). Firm Default Prediction: A Bayesian Model-Averaging Approach Journal of Financial and Quantitative Analysis, 52(3), 1211-1245. http://dx.doi.org/10.1017/S002210901700031X

Zenzerović, R. (2009). Business Financial Problem Prediction-Croatian Experience. Ekonomska Istraživanja, 22(4) 1-16. http://dx.doi.org/10.1080/1331677X.2009.11517387

Zhang, G. P., Hu, M. J., Patuwo E. B., \& Indro D. C. (1999). Artificial Neural Networks in Bankruptcy Prediction: General Framework and Cross-Validation Analysis. European Journal of Operational Research, 116(1), 16-32. http://dx.doi.org/10.1016/S0377-2217(98)00051-4

\section{Notes}

Note 1. The CERVED Database includes complete financial records of over 1.000,000 Italian companies.

Note 2. In this study, the terms defaulting/failing/failed/insolvent are used to refer to firms that underwent formal legal proceedings for debt in 2016 (bankruptcy procedures, forced liquidation, etc.).

Note 3. Central Italy consists of the following regions: Abruzzo, Emilia Romagna, Lazio, Liguria, Marche, Toscana, Umbria.

Note 4. This is a well-known heuristic method with low computational complexity. It often gives satisfactory results. In this method, each of the $n$ variables is tried, one at a time, and one-variable $n$ linear regression models are constructed. The variable $\left(X^{(l)}\right)$ which gives the "best" model $\left(\mathrm{Y}=\mathrm{a}+\mathrm{b}_{1} \mathrm{X}^{(1)}\right)$ is the first to be selected. Each of the other $X_{i}$ variables is examined (excluding $X^{(1)}$, which has already been selected), and the $X^{(2)}$ variable is selected. This is the variable presenting the "best behaviour" when placed in a regression model with two independent variables, one being $X^{(l)}$. Hence the model: $\mathrm{Y}=\mathrm{a}+\mathrm{b}_{1} \mathrm{X}^{(1)}+\mathrm{b}_{2} \mathrm{X}^{(2)}$ is the best two variable model 
when one variable is $X^{(1)}$. The third variable is selected using the same criteria; and the process is repeated until no new variables make any significant contribution to the model, or until the selection of a predetermined number of variables has been achieved.

Note 5. All the validity tests used in this study in order to verify research hypotheses (whose results are shown in Tables 7, 8 and 9) were implemented by verifying on the holdout samples (which are described in Section "4.1 The Sample Analyzed") the effectiveness of the predictive discriminant functions developed using the training samples (which are described in the same Section "4.1).

\section{Copyrights}

Copyright for this article is retained by the author(s), with first publication rights granted to the journal.

This is an open-access article distributed under the terms and conditions of the Creative Commons Attribution license (http://creativecommons.org/licenses/by/4.0/). 